\title{
Adubação nitrogenada no feijoeiro cultivado sob plantio direto em sucessão de culturas
}

\author{
Pedro Marques da Silveira( ${ }^{(1)}$, Antônio Joaquim Braga Pereira Braz ${ }^{(2)}$, Huberto José Kliemann ${ }^{(3)}$ \\ e Francisco José Pfeilsticker Zimmermann ${ }^{(1)}$
}

\begin{abstract}
(1)Embrapa Arroz e Feijão, Caixa Postal 179, CEP 75375-000 Santo Antônio de Goiás, GO. E-mail: pmarques@cnpaf.embrapa.br, fjpz@cnpaf.embrapa.br (2)Fundação de Ensino Superior de Rio Verde, Caixa Postal 104, CEP 75900-000 Rio Verde, GO. E-mail: antoniobraz@cultura.com.br (3)Universidade Federal de Goiás, Caixa Postal 131, CEP74001-970 Goiânia, GO. E-mail: kliemann@agro.ufg.br
\end{abstract}

Resumo - O nitrogênio é um nutriente essencial ao feijoeiro e sua carência é observada em quase todos os solos. O objetivo deste trabalho foi avaliar a resposta do feijoeiro irrigado por aspersão à adubação nitrogenada em cobertura, num Latossolo Vermelho distrófico. O cultivo foi realizado em sistema pivô central, em condições de plantio direto com sucessão de diferentes culturas. Os tratamentos constituíram-se de sete culturas: braquiária cv. Marandu, milho em consórcio com braquiária, guandu, milheto, mombaça, sorgo granífero e estilosantes cv. Mineirão. Sobre as palhadas picadas das culturas, foi semeado o feijão cv. Pérola e aplicados em cobertura 0 , 30,60 e $120 \mathrm{~kg} \mathrm{ha}^{-1}$ de $\mathrm{N}$ (uréia). Houve efeito das palhadas sobre a produtividade de grãos e as maiores produtividades alcançadas foram sobre as palhadas de milheto e do guandu. $\mathrm{O}$ feijoeiro responde à aplicação de $\mathrm{N}$ em cobertura em todas as sucessões, com resposta quadrática sobre o milheto e o guandu, e linear nas demais.

Termos para indexação: Phaseolus vulgaris, gramíneas, leguminosas, nitrogênio, adubação de cobertura.

\section{Nitrogen fertilization of common bean grown under no-tillage system after several cover crops}

\begin{abstract}
Nitrogen is an essential nutrient to common bean and its shortage is observed in almost all types of soils. The objective of this work was to evaluate the performance of irrigated common bean grown under no-tillage in succession to different cover crops and in relation to nitrogen topdressing fertilization in a Dystrophic Red Latosol (Typic Hapludox). The treatments were seven cover crops: Brachiaria brizantha cv. Marandu, B. brizantha associated with corn (Zea mays L.), pigeon pea (Cajanus cajan L. Millisp), millet (Pennisetum glaucum L. R. Br.), Panicum maximum cv. Mombaça, sorghum (Sorghum bicolor L. Moench) and Stylosanthes guianensis cv. Mineirão. The bean crop (cv. Perola) was seeded on the cover crop and 0, 30, 60, and $120 \mathrm{~kg} \mathrm{ha}^{-1}$ of N (urea) were topdressed. The cover crops affected the common bean grain yield. The highest grain yields were attained on millet and pigeon pea mulches. The common bean grain yield showed response to nitrogen topdressing fertilization on all cover crops. The response was quadratic on millet and pigeon pea mulches and linear on the other cover crops.
\end{abstract}

Index terms: Phaseolus vulgaris, grass, leguminous, nitrogen, topdressing fertilization.

\section{Introdução}

Embora grande quantidade de $\mathrm{N}$ possa estar contida na parte aérea das culturas denominadas de cobertura do solo, a quantidade real de $\mathrm{N}$ aproveitada pela cultura em sucessão dependerá do sincronismo entre a decomposição da fitomassa e a taxa de demanda da cultura sucessora. Portanto, a estimativa da quantidade de $\mathrm{N}$ disponibilizada é fundamental para se determinar a dose de $\mathrm{N}$ a ser fornecida via adubação mineral, seguindo os critérios de produtividade, retorno econômico e preservação ambiental.
Alvarenga et al. (2001) relataram que, na escolha das plantas de cobertura, o conhecimento da sua adaptação à região e da habilidade em se desenvolver num ambiente menos favorável, é um fator decisivo. Além disso, devem ser considerados a produção de fitomassa, as condições do solo, a tolerância ao déficit hídrico, a possibilidade de utilização em cultivo comercial e o potencial dessas plantas em serem hospedeiras de pragas e doenças.

No cerrado, com a introdução do milheto e do sorgo como culturas de cobertura, houve um incremento significativo da expansão do plantio direto na palha. Essas 
culturas proporcionam uma palhada mais duradoura na superfície do solo e, através de um sistema radicular mais agressivo, podem explorar amplo perfil do solo, extraindo e reciclando grandes quantidades de nutrientes não absorvidos pelas culturas principais, cultivadas no verão (Altmann, 2001).

As leguminosas desempenham um papel fundamental como fornecedoras de nutrientes, quando o sistema plantio direto está estabilizado, uma vez que as plantas dessa família têm a vantagem de prontamente disponibilizar nutrientes para culturas sucessoras, em virtude da rápida decomposição dos seus resíduos.

Segundo Floss (2000), as palhadas de gramíneas também são fornecedoras de nutrientes às culturas sucessoras a médio e longo prazo, especialmente na camada superficial. São exemplos os aumentos significativos dos teores de $\mathrm{P}$ e $\mathrm{K}$ nas camadas superficiais do solo no sistema plantio direto.

As espécies de plantas de cobertura do solo proporcionam efeito residual variável. Desse modo, sugere-se o uso de plantas com maior potencialidade para o aumento da produtividade das culturas de grande valor econômico em sucessão (Monegat, 1991).

Conforme Sano et al. (1999), grande parte da área dos cerrados, cerca de 50 milhões de hectares, é ocupada com pastagens cultivadas e gramíneas do gênero Brachiaria são as de maior ocorrência. Outras gramíneas e leguminosas cultivadas na região são mombaça (Panicum maximum cv. Mombaça), milheto (Pennisetum glaucum L.R. Br.), sorgo (Sorghum bicolor L. Moench), guandu-anão (Cajanus cajan L.) e estilosantes (Stylosanthes guianensis cv. Mineirão).

São relativamente recentes os estudos acerca da influência dos resíduos culturais deixados na superfície do solo sobre a produtividade de culturas cultivadas em sucessão. Garcia et al. (2003) verificaram a influência de plantas de cobertura sobre os componentes de produção da cultura do feijoeiro de inverno. As produtividades de grãos variaram em razão da cultura precedente. Wutke et al. (1998) também avaliaram o efeito residual de culturas graníferas e adubos verdes, e as produtividades médias obtidas pelo feijoeiro irrigado de $1.826 \mathrm{~kg} \mathrm{ha}^{-1}$ após o milho e de $1.672 \mathrm{~kg} \mathrm{ha}^{-1} \mathrm{em}$ sucessão ao guandu.

O objetivo deste trabalho foi avaliar a resposta do feijoeiro irrigado por aspersão, sistema pivô central, cultivado em condições de plantio direto em sucessão de várias culturas, à adubação nitrogenada em cobertura, num Latossolo Vermelho distrófico.

\section{Material e Métodos}

O experimento foi instalado em área com plantio direto na palha, manejado por cinco anos consecutivos, na Fazenda Capivara, pertencente à Embrapa Arroz e Feijão, no Município de Santo Antônio de Goiás, GO (latitude $16^{\circ} 28^{\prime} 0^{\prime \prime} \mathrm{S}$, longitude $49^{\circ} 17^{\prime} 0^{\prime \prime} \mathrm{W}$ e altitude de $823 \mathrm{~m})$.

O solo do local é classificado como Latossolo Vermelho distrófico, e a análise química (0-20 cm de profundidade) antes da instalação do experimento apresentou os seguintes valores: $\mathrm{pH}\left(\mathrm{H}_{2} \mathrm{O}\right), 5,7$; $\mathrm{Ca}\left(\mathrm{mmol}_{\mathrm{c}} \mathrm{dm}^{-3}\right), 20,5$; $\mathrm{Mg}\left(\mathrm{mmol}_{\mathrm{C}} \mathrm{dm}^{-3}\right), 7,4 ; \mathrm{P}\left(\mathrm{mg} \mathrm{dm}^{-3}\right), 21,5 ; \mathrm{K}\left(\mathrm{mg} \mathrm{dm}^{-3}\right), 101$; $\mathrm{Cu}\left(\mathrm{mg} \mathrm{dm}^{-3}\right), 2,2 ; \mathrm{Zn}\left(\mathrm{mg} \mathrm{dm}^{-3}\right), 8,1 ; \mathrm{Fe}\left(\mathrm{mg} \mathrm{dm}^{-3}\right), 62$; Mn (mg dm$\left.{ }^{-3}\right)$, 14; MO $\left(\mathrm{g} \mathrm{dm}^{-3}\right)$, 19. A análise gronulométrica apresentou os valores: areia $\left(\mathrm{g} \mathrm{kg}^{-1}\right), 490$; silte $\left(\mathrm{g} \mathrm{kg}^{-1}\right), 270$; e argila $\left(\mathrm{g} \mathrm{kg}^{-1}\right), 240$, segundo metodologia da Embrapa (1997).

Os tratamentos foram constituídos pelas seguintes culturas de cobertura de solo, semeadas em dezembro de 2001: braquiária (Brachiaria brizantha cv. Marandu), braquiária em consórcio com milho (Zea mays L.) - híbrido HT BRS 3150 -, guandu-anão (Cajanus cajan L. Millisp), milheto (Pennisetum glaucum L. R. Br.) - cv. BN-2 -, mombaça (Panicum maximum cv. Mombaça), sorgo granífero (Sorghum bicolor L. Moench) - cultivar BR 304 - e estilosantes (Stylosanthes guianensis) - cv. Mineirão. A área de cada parcela era de $127 \mathrm{~m}^{2}$ (6x20 m). Por ocasião da semeadura, aplicaram-se mecanicamente $400 \mathrm{~kg} \mathrm{ha}^{-1} \mathrm{da}$ fórmula comercial de adubo 5-30-15.

O consumo de sementes no plantio foi de $20 \mathrm{~kg} \mathrm{ha}^{-1}$ (braquiária, mombaça e milho), $25 \mathrm{~kg} \mathrm{ha}^{-1}$ (guandu), $40 \mathrm{~kg} \mathrm{ha}^{-1}$ (milheto), $10 \mathrm{~kg} \mathrm{ha}^{-1}$ (sorgo) e $1,4 \mathrm{~kg} \mathrm{ha}^{-1}$ (estilosantes).

Plantas de todas as culturas foram cortadas no mesmo dia, utilizando-se um triturador de palhada e deixadas na superfície do solo. Antes do corte, foram colhidos os grãos de milho e sorgo, mas não os de guandu, milheto e braquiária. O estilosantes se encontrava no estádio vegetativo.

Sessenta dias após o corte das culturas, realizou-se a semeadura do feijão. $\mathrm{O}$ ensaio foi instalado seguindo o delineamento experimental de blocos ao acaso, em esquema fatorial $7 \times 4$, com quatro repetições, sendo as parcelas constituídas pelas palhadas das culturas e as subparcelas, pelas doses de nitrogênio. As subparcelas foram constituídas de oito linhas de $5 \mathrm{~m}$ de comprimento, espaçadas de $0,45 \mathrm{~m}$. 
Antes do plantio do feijão, foi aplicado o herbicida glifosate $\left(2,4 \mathrm{~kg} \mathrm{ha}^{-1}\right.$ de i.a.). Na semeadura do feijão cv. Pérola em plantio direto, em 12/6/2002, a semeadora/adubadora foi regulada para distribuir de 15 a 18 sementes por metro. Nesta ocasião aplicaram-se $400 \mathrm{~kg} \mathrm{ha}^{-1} \mathrm{da}$ fórmula comercial 4-20-20. Foram utilizados 0, 30, 60 e $120 \mathrm{~kg} \mathrm{ha}^{-1}$ de $\mathrm{N}$ em cobertura (uréia). Metade da dose foi aplicada aos 15 dias e o restante, aos 25 dias após a emergência das plantas.

As irrigações foram realizadas por aspersão, sistema pivô central, quando a média das leituras do potencial da água do solo de três tensiômetros, instalados na área, a $0,15 \mathrm{~m}$ de profundidade, situava-se no intervalo entre $-0,03$ e $-0,04 \mathrm{MPa}$.

Os dados obtidos foram submetidos à análise de variância e as médias dos tratamentos comparadas pelo teste de Scott \& Knott (1974) a 5\% de probabilidade. Também foi realizado estudo de regressão polinomial, linear e quadrática, da produtividade de grãos em função das doses de nitrogênio.

\section{Resultados e Discussão}

As maiores produtividades de grãos do feijoeiro foram obtidas sobre as palhadas do milheto e do guandu (Tabela 1). A maior produtividade sobre a palhada do milheto provavelmente está relacionada com a alta capacidade de extração de nutrientes dessa planta (Pitol, 1999), disponibilizando-os para o feijoeiro. Oliveira et al. (2002), trabalhando com várias culturas de cobertura, relataram que o milheto foi a que proporcionou maior acúmulo de macronutrientes no solo para o cultivo seguinte. Dentre outras características, o milheto se destaca por apresentar um sistema radicular com capaci- dade de atingir maiores profundidades no perfil do solo, bem como uma alta capacidade de extração de nutrientes (Pitol, 1999).

As produtividades do feijoeiro foram de 2.175, 2.197 e $1.504 \mathrm{~kg} \mathrm{ha}^{-1}$, respectivamente, sobre as palhadas do guandu, milheto e braquiária. Garcia et al. (2003), utilizando as mesmas palhadas, obtiveram produtividades de, respectivamente, 1.346, 1.373 e $1.322 \mathrm{~kg} \mathrm{ha}^{-1}$, inferiores às obtidas neste trabalho, porém na mesma seqüência de grandeza. Wutke et al. (1998) alcançaram produtividade média do feijoeiro de $1.672 \mathrm{~kg} \mathrm{ha}^{-1}$ sobre os resíduos do guandu, enquanto Silva (2002) obteve $2.046 \mathrm{~kg} \mathrm{ha}^{-1}$ sobre a palhada do milheto.

Silveira et al. (2001), analisando o comportamento do feijoeiro cultivado em diferentes rotações de culturas, observaram que as menores produtividades foram obtidas nas rotações cuja cultura antecedente era o milho, semelhante ao verificado neste trabalho. Houve diferenças significativas entre as médias dos tratamentos em relação ao número de vagens por planta e ao estande (Tabela 1).

Garcia et al. (2003), trabalhando com palhadas de guandu, milheto e braquiária, encontraram variação dos componentes da produtividade do feijoeiro em função do tipo de palhada. A variação dos valores encontrados de estande do feijoeiro é, provavelmente, decorrente do volume da palhada das culturas, dificultando a operação de plantio.

Houve efeito significativo do N sobre a produtividade de feijão em todas as palhadas das culturas. Verificouse efeito quadrático nos tratamentos com milheto e guandu e linear nos tratamentos com sorgo, estilosantes, mombaça, braquiária e braquiária em consórcio com milho (Tabela 2). Na cobertura de milheto, de acordo

Tabela 1. Produtividade de matéria seca das culturas de cobertura, produtividade de grãos do feijoeiro (cv. Pérola), número de grãos por vagem, número de vagens por planta, estande e massa de 100 grãos sobre palhadas das culturas de

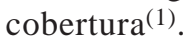

\begin{tabular}{|c|c|c|c|c|c|c|}
\hline Cultura de cobertura & $\begin{array}{l}\text { Matéria seca das } \\
\text { culturas }\left(\mathrm{kg} \mathrm{ha}^{-1}\right)\end{array}$ & $\begin{array}{c}\text { Grãos } \\
\left(\mathrm{kg} \mathrm{ha}^{-1}\right)\end{array}$ & $\begin{array}{c}\mathrm{N}^{\mathrm{o}} \text { de grãos } \\
\text { vagem }^{-1}\end{array}$ & $\begin{array}{c}\mathrm{N}^{\mathrm{o}} \text { de vagens } \\
\text { planta }^{-1}\end{array}$ & $\begin{array}{c}\text { Estande } \\
\left(\text { plantas } \mathrm{m}^{-2}\right)\end{array}$ & $\begin{array}{c}\text { Massa de } \\
100 \text { grãos }(\mathrm{g})\end{array}$ \\
\hline Braquiária & 12.480 & $1.505 \mathrm{~b}$ & $3,1 \mathrm{a}$ & $11,6 \mathrm{a}$ & $35,6 \mathrm{a}$ & $24,1 \mathrm{a}$ \\
\hline Milho e braquiária & 3.640 & $1.271 \mathrm{~b}$ & $3,8 \mathrm{a}$ & $8,9 \mathrm{~b}$ & $32,1 \mathrm{a}$ & $24,0 \mathrm{a}$ \\
\hline Guandu & 5.507 & $2.175 \mathrm{a}$ & $4,0 \mathrm{a}$ & $6,9 b$ & $35,5 \mathrm{a}$ & $26,7 a$ \\
\hline Milheto & 4.687 & $2.197 \mathrm{a}$ & $4,0 \mathrm{a}$ & $8,2 b$ & $36,2 \mathrm{a}$ & $24,8 \mathrm{a}$ \\
\hline Mombaça & 8.467 & $1.594 b$ & $3,4 \mathrm{a}$ & $10,1 \mathrm{a}$ & $30,7 b$ & $24,6 a$ \\
\hline Sorgo & 6.537 & $1.587 \mathrm{~b}$ & $3,8 \mathrm{a}$ & $7,8 \mathrm{~b}$ & $34,0 \mathrm{~b}$ & $25,8 \mathrm{a}$ \\
\hline Estilosantes & 3.494 & $1.536 \mathrm{~b}$ & $3,8 \mathrm{a}$ & $5,6 b$ & $36,0 \mathrm{~b}$ & $25,9 a$ \\
\hline
\end{tabular}

${ }^{(1)}$ Médias seguidas pela mesma letra, na coluna, não diferem entre si pelo teste de Scott \& Knott, a 5\% de probabilidade; o coeficiente de variação da produtividade de grãos foi de $19,26 \%$. 
com a equação de regressão ajustada, a máxima produtividade do feijoeiro foi de $2.504 \mathrm{~kg} \mathrm{ha}^{-1}$, obtida com a dose de $87 \mathrm{~kg} \mathrm{ha}^{-1}$ de nitrogênio. Em relação ao guandu, a produtividade máxima, de acordo com o modelo, foi de $2.507 \mathrm{~kg} \mathrm{ha}^{-1}$, praticamente igual à do milheto. Entretanto, foram necessários $107 \mathrm{~kg} \mathrm{ha}^{-1}$ de $\mathrm{N}$, ou seja, $20 \mathrm{~kg}$ a mais do aplicado para o milheto alcançar esta mesma produtividade. Pode-se inferir que a palhada de milheto restituiu mais $\mathrm{N}$ ao solo do que o guandu.

Silva et al. (2003) encontraram valores de 222 e $275 \mathrm{~kg} \mathrm{ha}^{-1}$ de $\mathrm{N}$ e K, respectivamente, como quantidades restituídas ao solo pelo milheto cortado aos 55 dias após semeadura. Estas quantidades dependem do teor no limbo foliar e da produtividade de matéria seca da cultura. Bonamigo (1999) observou teor de N de $34,2 \mathrm{~g} \mathrm{~kg}^{-1}$ nas folhas de milheto, valor considerado adequado para a cultura.

Silveira \& Damasceno (1993) avaliaram os efeitos de doses de $\mathrm{N}$ na produtividade de grãos do feijoeiro e obtiveram uma resposta quadrática. Silva (1998) verificou resposta quadrática na produtividade de grãos do feijoeiro em razão de doses de $\mathrm{N}$, em dois anos de ensaios, após a rotação arroz-calopogônio-feijão, utilizando grade aradora no preparo do solo; porém, na rotação milho-feijão, em plantio direto contínuo, a resposta foi linear.

Silveira et al. (2003), avaliando o efeito do N no feijoeiro cv. Pérola, estimaram produtividade máxima de $2.449 \mathrm{~kg} \mathrm{ha}^{-1}$, com a dose de $62 \mathrm{~kg} \mathrm{ha}^{-1} \mathrm{de} \mathrm{N}$, inferior à obtida neste trabalho sobre a palhada de guandu, que foi de $2.507 \mathrm{~kg} \mathrm{ha}^{-1}$, na dose máxima de $87 \mathrm{~kg} \mathrm{ha}^{-1}$ de nitrogênio.

Nas palhadas de braquiária, milho em consórcio com braquiária, mombaça, sorgo e estilosantes, a dose de $120 \mathrm{~kg} \mathrm{ha}^{-1}$ de $\mathrm{N}$ não foi suficiente para se atingir a produtividade máxima do feijoeiro. As menores produtivi-

Tabela 2. Equações de regressão entre produtividade de grãos do feijoeiro (cv. Pérola) e doses de nitrogênio, nas palhadas das diversas culturas de cobertura.

\begin{tabular}{lcc}
\hline $\begin{array}{l}\text { Cultura de } \\
\text { cobertura }\end{array}$ & Equação de regressão & $\mathrm{r}^{2}$ ou $\mathrm{R}^{2}$ \\
\hline Braquiária & $\mathrm{Y}=1.247,57+4,90 \mathrm{~N}$ & $0,71^{*}$ \\
Milho e braquiária & $\mathrm{Y}=1.005,13+5,06 \mathrm{~N}$ & $0,60^{*}$ \\
Milheto & $\mathrm{Y}=1.773,45+16,75 \mathrm{~N}+0,096 \mathrm{~N}^{2}$ & $0,99^{* *}$ \\
Guandu & $\mathrm{Y}=1.737,59+14,36 \mathrm{~N}+0,067 \mathrm{~N}^{2}$ & $0,83^{*}$ \\
Mombaça & $\mathrm{Y}=1.320,26+5,21 \mathrm{~N}$ & $0,95^{* *}$ \\
Sorgo & $\mathrm{Y}=1.332,80+4,84 \mathrm{~N}$ & $0,96^{* *}$ \\
Estilosantes & $\mathrm{Y}=1.295,32+4,59 \mathrm{~N}$ & $0,76^{*}$ \\
\hline
\end{tabular}

* e **Significativo a $5 \%$ e a $1 \%$ de probabilidade, respectivamente, pelo teste t. dades ocorreram quando a cultura antecedente foi o consórcio milho e braquiária em qualquer dose de nitrogênio.

Silveira et al. (2001), analisando o comportamento do feijoeiro cultivado em diferentes rotações, observaram que as menores produtividades foram obtidas nas rotações que apresentaram a cultura do milho como antecessora, semelhante ao que ocorreu no presente trabalho. A menor produtividade do feijoeiro pode ser atribuída, em parte, à maior competição dos microrganismos pelo nutriente, durante a decomposição da palhada do milho que, por sua relação $\mathrm{C} / \mathrm{N}$ e tamanho dos resíduos, é mais demorada que a de outras plantas, principalmente leguminosas. Existem referências de que em situação semelhante a esta, ou seja, em sucessão à cultura do milho, o feijoeiro deve receber maior quantidade de nitrogênio (Embrapa, 1989; Salgado et al., 1992).

Conforme as equações de regressão, para atingir uma produtividade de $1.600 \mathrm{~kg} \mathrm{ha}^{-1}$ de feijão, são necessários $118,72,54,55$ e $66 \mathrm{~kg} \mathrm{ha}^{-1}$ de $\mathrm{N}$, respectivamente, quando o mesmo é cultivado sobre as palhadas de braquiária, milho em consórcio com braquiária, mombaça, sorgo e estilosantes. Tomando como referência o valor de $118 \mathrm{~kg} \mathrm{ha}^{-1}$ de $\mathrm{N}$ necessário na sucessão milho e braquiária, houve economia de 39\%, 54\%, $53 \%$ e $44 \%$ na quantidade de $\mathrm{N}$ em cobertura, respectivamente, quando foram utilizadas as palhadas de braquiária, mombaça, sorgo e estilosantes, para alcançar aquela produtividade.

\section{Conclusões}

1. Há efeitos das culturas antecedentes sobre a produtividade de grãos do feijoeiro em sucessão.

2. A produtividade de grãos do feijoeiro obedece a uma função quadrática em resposta à adubação nitrogenada nas palhadas do milheto e do guandu, e a produtividade máxima é alcançada no milheto com menor dose de nitrogênio.

3. Nas palhadas de braquiária, milho em consórcio com braquiária, sorgo, mombaça e estilosantes, a resposta do feijoeiro à adubação nitrogenada é linear até a dose de $120 \mathrm{~kg} \mathrm{ha}^{-1}$ de nitrogênio.

4. Na mesma produtividade de grãos do feijoeiro, a quantidade necessária de $\mathrm{N}$ em cobertura é decrescente quando cultivado sobre as palhadas de milho em consórcio com braquiária, braquiária, estilosantes, sorgo e mombaça. 


\section{Referências}

ALTMANN, N. Rotação de culturas: base da cobertura permanente do solo e da sustentabilidade em SPD. In: ENCONTRO REGIONAL DE PLANTIO DIRETO NO CERRADO, 5., 2001, Dourados. Anais. Dourados: Embrapa Agropecuária Oeste, 2001. p.29-30.

ALVARENGA, R.C.; CABEZAS, W.A.L.; CRUZ, J.C.; SANTANA, D.P. Plantas de cobertura de solo para sistema plantio direto. Informe Agropecuário, v.22, p.25-36, 2001.

BONAMIGO, L.A. A cultura do milheto no Brasil: implantação e desenvolvimento no Cerrado. In: WORKSHOP INTERNACIONAL DE MILHETO, 1999, Planaltina, DF. Anais. Planaltina: Embrapa Cerrados, 1999. p.31-65.

EMBRAPA. Centro Nacional de Pesquisa de Arroz e Feijão (Goiânia, GO). Informações técnicas para o cultivo de feijão irrigado (GO, DF, MG, ES, SP, RJ). Goiânia: Embrapa-CNPAF, 1989. 35p. (Embrapa-CNPAF. Circular Técnica, 23).

EMBRAPA. Centro Nacional de Pesquisa de Solos (Rio de Janeiro, RJ). Manual de métodos de análise de solo. 2.ed. Rio de Janeiro, 1997. 212p. (Embrapa-CNPS. Documentos, 1).

FLOSS, E.L. Benefícios da biomassa de aveia ao sistema de semeadura direta. Revista Plantio Direto, v.57, p.25-29, 2000.

GARCIA, R.N.; FORNASIERI FILHO, D.; ROSSATO JÚNIOR, J.A. de S. Influência de cultura de cobertura morta e nitrogênio sobre os componentes produtivos da cultura do feijoeiro de inverno em sucessão a cultura do milho. In: CONGRESSO BRASILEIRO DE CIÊNCIA DO SOLO, 29., 2003, Ribeirão Preto. Anais. Ribeirão Preto: Sociedade Brasileira de Ciência do Solo, 2003. 1 CDROM.

MONEGAT, C. Plantas de cobertura do solo: características e manejo em pequenas propriedades. Chapecó: Ed. do autor, 1991. 337p.

OLIVEIRA, T.K. de; CARVALHO, G.J. de; MORAES, R.N.S. Plantas de cobertura e seus efeitos sobre o feijoeiro em plantio direto. Pesquisa Agropecuária Brasileira, v.37, p.1079-1087, 2002.

PITOL, C. O milheto em sistemas de plantio direto. In: WORKSHOP INTERNACIONAL DE MILHETO, 1999, Planaltina, DF. Anais. Planaltina: Embrapa Cerrados, 1999. p.69-71.
SALGADO, L.T.; ARAÚJO, G.A.A.; VIEIRA, R.F. Efeito de espaçamento e época de aplicação de nitrogênio em dois cultivares de feijão no outono-inverno. In: Epamig (Belo Horizonte, MG). Projeto Feijão: relatório 88/92. Viçosa, 1992. p.19-22.

SANO, E.E.; BARCELLOS, A. de O.; BEZERRA, H.S. Área e distribuição espacial de pastagens cultivadas no cerrado brasileiro. Planaltina: Embrapa Cerrados, 1999. 21p. (Embrapa Cerrados. Boletim de Pesquisa, 3).

SCOTT, A.J.; KNOTT, M.A. A cluster analysis method for grouping means in the analysis of variance. Biometrics, v.30, p.507-512, 1974.

SILVA, C.C. da. Influência de sistemas agrícolas em características do solo e na resposta do feijoeiro (Phaseolus vulgaris L.) irrigado à adubação nitrogenada em cobertura. 1998. 116p. Tese (Doutorado) - Universidade Federal de Goiás, Goiânia.

SILVA, F.L.; COLLIER, L.S.; LAURINDO, P.C.; MENDES, M.M.; FISHER, E.C. Potencial de restituição de nutrientes através de plantas de cobertura em plantio direto no Tocantins. In: CONGRESSO BRASILEIRO DE CIÊNCIA DO SOLO, 29., 2003, Ribeirão Preto. Anais. Ribeirão Preto: Sociedade Brasileira de Ciência do Solo, 2003. 1 CD-ROM.

SILVA, T.R.B. da. Adubação nitrogenada e resíduos vegetais no desenvolvimento do feijoeiro (Phaseolus vulgaris L.) em sistema plantio direto. 2002. 56p. Dissertação (Mestrado) - Universidade Estadual Paulista, Ilha Solteira.

SILVEIRA, P.M. da; BRAZ, A.J.B.P.; DIDONET, A.D. Uso do clorofilômetro como indicador da necessidade de adubação nitrogenada em cobertura no feijão. Pesquisa Agropecuária Brasileira, v.38, p.1083-1087, 2003.

SILVEIRA, P.M. da; DAMASCENO, M.A. Doses e parcelamento de K e de N, na cultura do feijoeiro irrigado. Pesquisa Agropecuária Brasileira, v.28, p.1269-1276, 1993.

SILVEIRA, P.M. da; SILVA, O.F. da; STONE, L.F.; SILVA, J.G. da. Efeitos do preparo do solo, plantio direto e de rotações de culturas sobre o rendimento e a economicidade do feijoeiro irrigado. Pesquisa Agropecuária Brasileira, v.36, p.257-263, 2001.

WUTKE, E.B.; FANCELLI, E.B.; PEREIRA, J.C.V.N.A.; AMBROSANO, G.M.B. Rendimento do feijoeiro irrigado em rotação com culturas graníferas e adubos verdes. Bragantia, v.57, p.325338, 1998.

Recebido em 22 de junho de 2004 e aprovado em 14 de setembro de 2004 